\title{
Model Development and Load Analysis of an Offshore Wind Turbine
}

\author{
Zhang Wei ${ }^{1}$, Liu Jie ${ }^{1}$ \\ College of Materials Science and Engineering, Shenzhen University, Shenzhen, P.R. China ${ }^{1}$
}

\begin{abstract}
Results of a study that investigates the feasibility of platforms that support a floating wind turbine are presented. Both theoretical and experimental studies are described. In the theoretical portion, the geometry of platforms with differing configurations is first modelled. The hydrodynamic coefficients were derived using WAMIT (Wave Analysis at MIT). An equation of motion was developed that incorporated these coefficients. The computer code FAST (Fatigue, Aerodynamics, Structures, and Turbulence) was used to add the effects of wind turbine and wave loads. In the final step, the wind turbine motion was calculated for six degrees of freedom with and without aerodynamic loads. In the experimental part, a water channel was used. A wide range of waves with different amplitudes and frequencies were generated within the channel. To verify the theoretical results, various model platforms were constructed and the hydrodynamic coefficients were derived to compare them with theoretical results.
\end{abstract}

Keywords: Offshore wind turbine, Load analysis, Hydrodynamic coefficients, Dynamic Analysis.

\section{INTRODUCTION}

Renewable energy resource, such as wind, solar and geothermal, wind is growing rapidly due to offering clean and domestic source of energy [1]. Wind power is among the fastest growing fields of alternative power generation methods. The energy can be generated without pollution and it is inexhaustible. Regional utility scale electricity generation through renewable sources such as wind enables region's economy to sustainably boost up. Many issues in combustive and fossil fuel based plants regarding emissions are being solved by switching to wind power electricity generation [2]. According to the U.S Energy Department, in 2012, wind energy became the number one source of new U.S. electricity generation for the first time - representing 43 percent of all new electric additions and accounting for $\$ 25$ billion in U.S. investment [3]. Last year, over 13 gigawatts $(\mathrm{GW})$ of new wind power capacity were added to the U.S. grid - nearly double the wind capacity deployed in 2011. This tremendous growth helped America's total wind power capacity surpass 60 GW at the end of 2012 - representing enough capacity to power more than 15 million homes annually, or as many homes as in the states of California and Washington combined. The country's cumulative installed wind energy capacity has increased more than 22-fold since 2000.

Professor William E. Heronemus was the first one to introduce the concept of an offshore wind turbine [3]. There are several project inside United States to develop offshore wind turbine [4], [5]. Advantage of offshore wind turbine are significant [6]. The wind tends to blow more strongly and consistently, with less turbulence intensity and there is smaller shear at sea than on land. The visual and noise annoyances of wind turbines can be avoided if the turbines are installed a sufficient distance from shore. Vast expanses of uninterrupted open sea are available and the installations will not occupy land, interfering with other land uses.
However, along with these advantages, there are also several disadvantages that include a higher capital investment [7] required for offshore wind turbines because of the costs associated with marinization of the turbine and the added complications of the foundation, support structure, installation, and decommissioning. In [8], the authors presented a new method for reducing losses in wind turbine by the optimization of the blade length using genetic algorithm. Offshore installations are less accessible than onshore installations, which raises the operations and maintenance costs and possibly increases the down time of the machines.

Not only do offshore wind turbines experience environmental loading from the wind, but they must also withstand other conditions, such as hydrodynamic loading from waves and sea currents. As a result, the complexity of the design increases. There are several types of offshore floating platforms. The stability of each platform can be achieved by three different methods. These methods are restoring from water plane area, from ballast and from mooring lines. All these methods will be discussed here [7].

Each offshore wind turbine has three main elements: the wind turbine (the main structure), the platform and the mooring line. The platform supports the wind turbine and limits its motion in all six degrees of freedom. The electrical components of wind turbine include electric machines recently of axial permanent-magnet type [9], [10], power electronic interface, and transformers. In order to be able to design the platform, first we need to know the force which is exerted on the platform by the wind turbine, the sea waves and the mooring lines.

Structural health monitoring of wind turbine blades is still a major problem which restricts wider usage of wind energy. Thanks to the newly developed SHM and FEM 
methods [11-14], there are new hope in wider usage of wind energy.

Despite the advantages of wind energy structural health monitoring (SHM) of wind turbine blades is a major problem. Wind turbines are vulnerable to lightning strikes, and the blades are hit by lightning strikes at least once a year. The tip of the blade of a wind turbine is the part that is most likely to receive a lighting arc. Composite materials are used in construction of the wind turbine. Gharghabi et al. [15] investigated the effect of the lightning strike on the composite structure and showed that it can have visible and residual effect on the material properties. Direct effects of lightning strike to an object can be are visible at the skin of the blade, and can also change the material property inside the structure of the blade [16].

Forces of the wind turbine are mainly due to the wind. In this study calculation of aerodynamic forces on the turbine was made using the computer code FAST (Fatigue, Aerodynamics, Structures, and Turbulence), which was developed at NREL (National Renewable Energy Laboratory) and is publicly available. The first step in the procedure is to model the wind turbine in the software. In these studies, the NREL 5-MW wind turbine, which represents a typical state of the art multi megawatt turbine, was used as the model. Next the environmental conditions in which wind turbine is going to operate were prescribed. Premier among the parameters that are important is the wind speed. Also, it should be noted whether the wind is steady or turbulent. This information allows the software to calculate the aerodynamic force on the turbine.

The wave loads were calculated using the computer code WAMIT (Wave Analysis at MIT). The first step is to model the geometry of the platform. The geometry can be described in two ways. One method is to represent the platform by an ensemble of flat quadrilateral panels or facets. In the second method the platform's geometry may be represented by an explicit analytical formula. Next the wave condition must be prescribed. The waves may be regular or irregular and periodic or non-periodic. Also, the free surface must be specified as an input to the software. This is especially important when extreme waves need to be modelled and non-linear effects are not negligible. After all of this the software may be run to produce the results.

A subroutine was written for the calculation of the force from the mooring line. The inputs for the subroutine are: the elastic modulus of the material, the water depth and the angle of the line. Finally, another module was constructed in order to calculate the motion of the whole system in the time domain. The hydrodynamic and aerodynamic forces and the force from the mooring line are inputs to this subprogram as are the mass, damping and stiffness matrices. In addition to the simulation results, a series of experiments were conducted in order to verify the results. The experiments were performed within a water channel. A wide range of waves with different amplitude were generated. Also different scale model platforms were built and hydrodynamic coefficients were measured for them

\section{A. Modelling the Offshore Wind Turbine}

The offshore wind turbine consists of three parts; the floating platform, the wind turbine and the mooring line. In this paper, each component is modelled separately and in the final stage all of the components will be considered together. In this section, details of the chosen wind turbine will be examined. Also, in the relevant sections different platforms and the mooring line which were chosen to be modelled will be considered.

In the simulation, it is assumed that the wind turbine and the platform are rigid. The translational along the $\mathrm{x}, \mathrm{y}$ and $\mathrm{z}$ axes are the modes 1-3 which are modes of surge, sway and heave. Respectively, rotational modes along $\mathrm{x}, \mathrm{y}$ and $\mathrm{z}$ are modes 4-6 which are rotational modes of roll, pitch and yaw. The equation of motion for the offshore wind turbine in matrix form may be written as:

$$
\begin{aligned}
& \sum_{\mathrm{k}=1}^{6}\left[\left(\mathrm{M}_{\mathrm{jk}}+\mathrm{A}_{\mathrm{jk}}\right) \ddot{\eta}_{\mathrm{k}}+\mathrm{B}_{\mathrm{jk}} \dot{\eta}_{\mathrm{k}}+\mathrm{C}_{\mathrm{jk}} \eta_{\mathrm{k}}\right] \\
& (\mathrm{j}=1, \ldots, 6) \quad=\mathrm{F}_{\mathrm{j}} \mathrm{e}^{\mathrm{i} \omega \mathrm{t}},
\end{aligned}
$$

The symbols which are used in Eq. (1) have the following meaning. $\eta_{\mathrm{k}}, \dot{\eta}_{\mathrm{k}}$ and $\ddot{\eta}_{\mathrm{k}}$ are 6 by 1 vectors which represent displacement, velocity and acceleration of the platform in its 6 modes of motion. $\omega$ is the wave frequency and $M$ and A are the 6 by 6 mass and added mass matrices. B and C are the 6 by 6 damping and restoring matrices. And finally $F$ is the 6 by 1 force vector. The displacement may be defined as

$$
\eta_{k}(t)=\operatorname{Re}\left\{\Xi e^{i \omega t}\right\}
$$

Substituting Eq. (2) into the equation of motion, Eq. (1) we get

$$
\begin{aligned}
& {\left[-\omega^{2}(M+A(\omega))+i \omega B(\omega)+C\right] \Xi(\omega)=F,} \\
& (j=1, \ldots, 6)
\end{aligned}
$$

In some studies, it has been indicated that a $5 \mathrm{MW}$ wind turbine is the minimum power that a deep floating wind turbine must have in order to be cost effective to build. The wind turbine which is studied in this study is the NREL-5 MW offshore baseline wind turbine model. The wind turbine is described in Table 1. The wind turbine described in Table 1 was analysed using the FAST computer code to obtain its characteristics. Let's assume that the centre of mass of our structure is at $\left(\mathrm{x}_{\mathrm{CG}}, \mathrm{y}_{\mathrm{CG}}, \mathrm{z}_{\mathrm{CG}}\right)$. So the mass matrix would be

$\mathrm{M}_{\text {Platform }}$

$=\left[\begin{array}{cccccc}\mathrm{m} & 0 & 0 & 0 & \mathrm{mz}_{\mathrm{CG}} & -\mathrm{r} \\ 0 & \mathrm{~m} & 0 & -\mathrm{mz}_{\mathrm{CG}} & 0 & \mathrm{~m} \\ 0 & 0 & \mathrm{~m} & \mathrm{my}_{\mathrm{CG}} & -\mathrm{mx}_{\mathrm{CG}} & \\ 0 & -\mathrm{mz}_{\mathrm{CG}} & \mathrm{my}_{\mathrm{CG}} & \mathrm{I}_{11} & \mathrm{I}_{12} & ] \\ \mathrm{mz}_{\mathrm{CG}} & 0 & -\mathrm{mx}_{\mathrm{CG}} & \mathrm{I}_{21} & \mathrm{I}_{22} & ] \\ -\mathrm{my}_{\mathrm{CG}} & \mathrm{mx}_{\mathrm{CG}} & 0 & \mathrm{I}_{31} & \mathrm{I}_{32} & ]\end{array}\right)$

The two platforms which were studied are Surface and Submerged MIT/NREL TLPs. The properties of these platforms are presented in Table 2. 
Vol. 4, Issue 3, March 2017

Table 1. Platform Properties of the MIT/NREL TLPs

\begin{tabular}{|c|c|}
\hline Rotor orientation & Upwind \\
\hline Control & $\begin{array}{l}\text { Variable speed, } \\
\text { Collective pitch }\end{array}$ \\
\hline $\begin{array}{l}\text { Rotor Diameter/ Hub } \\
\text { Diameter }\end{array}$ & $126 \mathrm{~m} / 3 \mathrm{~m}$ \\
\hline Hub Height & $90 \mathrm{~m}$ \\
\hline Max Rotor/ Generator & $12.1 \mathrm{rpm} / 1,173.7$ \\
\hline Speed & $\mathrm{rpm}$ \\
\hline Maximum Tip Speed & $80 \mathrm{~m} / \mathrm{s}$ \\
\hline Overhang/Shaft & $5 \mathrm{~m} / 5$ degree/ -2.5 \\
\hline Tilt/Precone & degree \\
\hline Rotor Mass & $110,000 \mathrm{Kg}$ \\
\hline Nacelle Mass & $240,000 \mathrm{Kg}$ \\
\hline Tower Mass & $347,460 \mathrm{KG}$ \\
\hline
\end{tabular}

The added mass, damping coefficients and hydrodynamic forces on platform are needed to numerically study the effects of wave on platform. To obtain these coefficients the WAMIT (Wave Analysis at MIT) was used. The geometry of the platform was defined using a Geometric Data File (GDF) [15]. It was reported that size of meshes $[18,19]$. It includes the Cartesian coordinates of each vertex of each panel, listed sequentially.

Table 2. Platform Properties of the MIT/NREL TLPs

\begin{tabular}{|c|c|c|c|}
\hline Property & $\begin{array}{c}\text { Surface } \\
\text { TLP }\end{array}$ & $\begin{array}{c}\text { Submerged } \\
\text { TLP }\end{array}$ & Units \\
\hline Radius & 11 & 11 & $\mathrm{M}$ \\
\hline $\begin{array}{c}\text { Cylinder } \\
\text { Height }\end{array}$ & 26 & 24 & M \\
\hline $\begin{array}{l}\text { Tower } \\
\text { Draft }\end{array}$ & 0 & 10 & M \\
\hline $\begin{array}{l}\text { Installed } \\
\text { Draft }\end{array}$ & 22.75 & 36 & M \\
\hline $\begin{array}{c}\text { Deck } \\
\text { Clearance }\end{array}$ & 3.25 & -10 & $\mathrm{M}$ \\
\hline $\begin{array}{c}\text { Center of } \\
\text { Gravity }\end{array}$ & -12.01 & -25.26 & M \\
\hline
\end{tabular}

The non-dimensional added mass terms, Eqs. (5) -(8), and the damping coefficients, Eqs. (9) -(12), were defined by dividing the added mass by the product of the water density and the volume of submerged structure $\left(\rho^{*} \mathrm{~V}\right)$, and dividing the damping coefficients by the product of the density, the volume of submerged structure, and the wave frequency $\left(\rho * V^{*} \omega\right)$. The dimensionless frequency was defined by multiplying the frequency by the root of the characteristic dimension divided by gravity constant.

$$
\begin{aligned}
& \bar{A}_{i j}=\frac{A_{i j}}{\rho_{\text {water }} L^{k}} \\
& k=3 \text { for }(i, j=1,2,3) \\
& k=4 \quad \text { for } \quad(i=1,2,3, j=4,5,6) \text { or }(j \\
& =1,2,3, i=4,5,6) \\
& k=5 \quad \text { for } \quad(i, j=4,5,6)
\end{aligned}
$$

$$
\begin{aligned}
& \bar{B}_{i j}=\frac{B_{i j}}{\rho_{\text {water }} L^{k} \omega} \\
& k=3 \quad \text { for } \quad(i, j=1,2,3) \\
& k=4 \quad \text { for } \quad(i=1,2,3, j=4,5,6) \text { or }(j \\
& k=5 \quad \text { for } \quad(i, j=1,2,3, i=4,5,6)
\end{aligned}
$$

The platform gains stiffness from three different sources. These sources are: the water plane, buoyancy and the mooring line.

The buoyancy of the platform depends on the rotation of the platform. Because of symmetry the only non-zero entries in the water plane restoring matrix are the diagonal entries for heave, pitch and roll. The stiffness is

$$
\begin{aligned}
& C_{33, \text { water plane }}=\rho g \iint d A=\rho g \pi R^{2} \\
& C_{44, \text { water plane }}=\rho g \iint x^{2} d A=\frac{\rho g \pi R^{4}}{4} \\
& C_{55, \text { water plane }}=\rho g \iint y^{2} d A=\frac{\rho g \pi R^{4}}{4}
\end{aligned}
$$

The stiffness can be obtained by lowering the centre of gravity in comparison to the centre of buoyancy:

$$
\begin{aligned}
& \text { Center of buoyancy }=\frac{d}{2} \\
& C_{44, \text { Buoyant }}=\frac{\rho g d m_{\text {bouyant }}}{2}-m_{\text {total }} g Z_{C G} \\
& C_{55, \text { Buoyant }}=\frac{\rho g d m_{\text {bouyant }}}{2}-m_{\text {total }} g Z_{C G}
\end{aligned}
$$

Stiffness can be added to the system by mooring lines. Among different mooring lines, the tension mooring line was chosen for this study. It was assumed that the mooring line is a straight line and that it does not enter to the plastic region and that the angle between our mooring line and imaginary horizontal line is $\theta$ The pre-tension of the mooring line is $F_{\text {Tether }}$.For a small imaginary displacement in the $\mathrm{x}$ direction to the platform, we may write

$$
\begin{gathered}
d F=F_{\text {Tether }}(\cos (\theta+d \theta)-\cos (\theta-d \theta)) \\
=-F_{\text {Tethers }} \sin (\theta) d \theta \\
d x=L_{\text {Tether }} \sin (\theta) \cdot d \theta \\
C_{11}=\frac{F_{\text {Tethers }}}{L_{\text {Tether }}}, \quad C_{22}=\frac{F_{\text {Tethers }}}{L_{\text {Tether }}}
\end{gathered}
$$

In the $\mathrm{z}$ direction, we have

$$
\Delta z=\frac{\Delta F L_{\text {Tether }}}{E_{\text {Tether }} A_{\text {Tether }}}, \quad c_{33}=\frac{E_{\text {Tether }} A_{\text {Tether }}}{L_{\text {Tether }}}
$$

And by writing the equilibrium equation around the centre we have

$$
\begin{aligned}
c_{44} & =\frac{2 E_{\text {Tether }} A_{\text {Tether }}}{L_{\text {Tether }}}\left(R^{2}\right), \\
c_{55} & =\frac{2 E_{\text {Tether }} A_{\text {Tether }}}{L_{\text {Tether }}}\left(R^{2}\right)
\end{aligned}
$$




$$
\begin{aligned}
& c_{66}=\frac{R^{2}}{L_{\text {Tether }}}\left(F_{B}-M_{11} g\right), \\
& c_{51}=c_{42}=-\frac{F_{\text {Tether }}}{L_{\text {Tether }}} T
\end{aligned}
$$

\section{EXPERIMENTAL WORK}

Water channel was used for experimental work. A wave generator was designed and built to simulate the wave loads experienced by an offshore wind turbine platform. Data were acquired at a rate of 10,000 samples per second, and each experiment was conducted for approximately 10 seconds after the results became steady.

In order to simulate the conditions on wind turbine, scalemodel platforms were built using ABS plastic. The platform is a cylinder with the length of $26 \mathrm{~cm}$ and diameter of $22 \mathrm{~cm}$.

To measure the force and torque applied to the platform, a Six-Axis Force/Torque Sensor (Nano 25, serial number FT11132) manufactured by ATI Industrial Automation was used. The load cells could measure force up to $125 \mathrm{~N}$ in all three directions and torque up to $3 \mathrm{~N}$-m in all three directions. Since the load cell measurement range is within the experiment, it is a good candidate to choose. The load cell signal was processed using software and hardware of the National Instruments data acquisition system.

To capture the depth of the water inside the channel, photographic measurement technique was used. The camera used in the experiment was PIVCAM 10-30 model 630046. The camera could take 25 pictures per second. The data from camera was processed using Insight software.

The experiments were conducted inside the water channel. The size of channel is 18 -inch-deep $\times 12$-inch-wide $\times 100$ inch-long. The wave generator is plank that oscillates upward and downward and generate waves inside the channel [20]. The wave height was measured using camera installed at the side of the channel. The period of wave was from 0.1 to 1 seconds and the wave heights were from 0 to $4 \mathrm{~cm}$.

The wave maker was powered by an electrical D.C motor. The power of D.C motor was 1.5 horsepower. In order to generate wave with different periods and height, the power of motor was changed during the experiment [21].

\section{POST PROCESSING OF DATA}

In order to establish a connection between the results from the experiments of the scale model with the results from the simulation of the full scale platform, Froude scale modelling was used. First, a geometric scaling ratio was defined as

$$
\lambda=\frac{L_{F S}}{L_{M}}
$$

Where $L_{F S}$ denotes the characteristic length of the full scale model and $L_{M}$ denotes the characteristic length of the model. The Froude number is defined as:

$$
F r=\frac{U}{\sqrt{g L}}
$$

In Eq. (26) $\mathrm{U}$ is the characteristic velocity, $\mathrm{L}$ is the characteristic length and $\mathrm{g}$ is the acceleration of gravity. The goal is to equalize the Froude number of the model with full scale platform. In order to accomplish that, we write

$$
F r_{m}=F r_{f s} \rightarrow U_{f s}=U_{M} \sqrt{\frac{L_{F S}}{L_{M}}}
$$

Equation. (27) can be written as.

$$
U_{f s}=U_{M} * \sqrt{\lambda}
$$

For other physical parameters, the same procedure can be conducted. For example, acceleration will change by the factor of 1 , while force varies by the scale of $\lambda 3$. The full

\begin{tabular}{|c|c|c|c|}
\hline Variable & Dimensions & Units & $\begin{array}{l}\text { Scale } \\
\text { Ratio }\end{array}$ \\
\hline Length & $\mathrm{L}$ & $\mathrm{m}$ & $\lambda$ \\
\hline Mass & M & $\mathrm{Kg}$ & $\lambda^{3}$ \\
\hline Angle & None & $\mathrm{Rad}$ & 1 \\
\hline Acceleration & $L / T^{2}$ & $\mathrm{~m} / \mathrm{s}^{2}$ & 1 \\
\hline $\begin{array}{l}\text { Angular } \\
\text { Acceleration }\end{array}$ & $1 / T^{2}$ & $1 / S^{2}$ & $\lambda^{-1}$ \\
\hline & $1 / T$ & $1 / s$ & $\frac{1}{\sqrt{\lambda}}$ \\
\hline Force & $(M * L) / T^{2}$ & $(k g * m) / S^{2}$ & $\lambda^{3}$ \\
\hline Wave Height & $L$ & $m$ & $\lambda$ \\
\hline Wave Period & $T$ & $S$ & $\sqrt{\lambda}$ \\
\hline Velocity & $L / T$ & $\mathrm{~m} / \mathrm{s}$ & $\sqrt{\lambda}$ \\
\hline $\begin{array}{l}\text { Moment of } \\
\text { Inertia }\end{array}$ & $M * L^{2}$ & $k g * m^{2}$ & $\lambda^{3}$ \\
\hline
\end{tabular}
lists of properties are listed in Table 3. The important issue in this analysis is that Reynolds number and Froude number of scale and full size platform could not be equalized at the same time $[22,23]$.

Table 3. Scale Factors for Each Variable

\section{IV.RESULTS}

Using the mesh created the geometric data file for WAMIT software $[24,25]$, the program was run to obtain hydrodynamic coefficients of the platforms which are studied in this research. The damping and added mass matrices are 6 by 6 and therefore have 36 components. Figure 1- 6 show these components for each matrix.

In Fig. 1 and Fig. 4, the plots of non-dimensional added mass for four different components were presented. It is understood from the figures that added mass will change a little as frequency changes in submerged platform, but it will change drastically in the surface platform. The main reason is that waves reaction to the platform is different at different frequencies. 

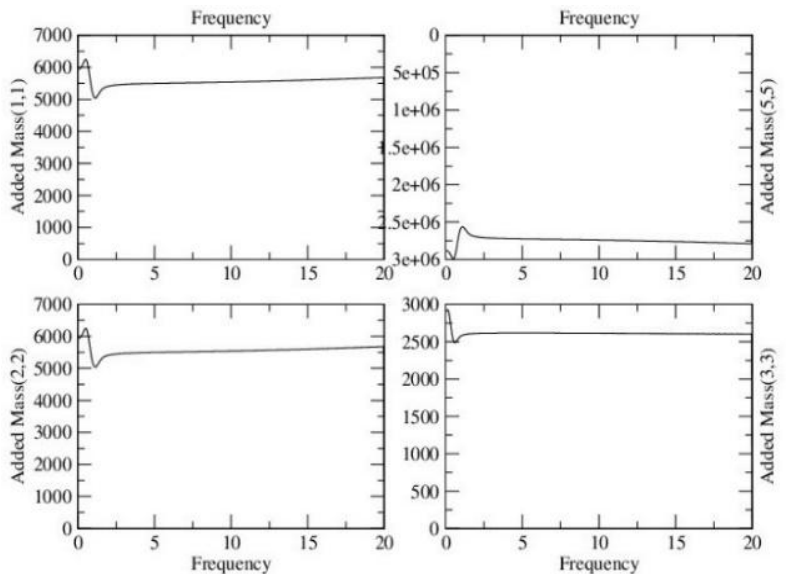

Figure 1. Added Mass Matrices, MIT/NREL TLP,

Submerged
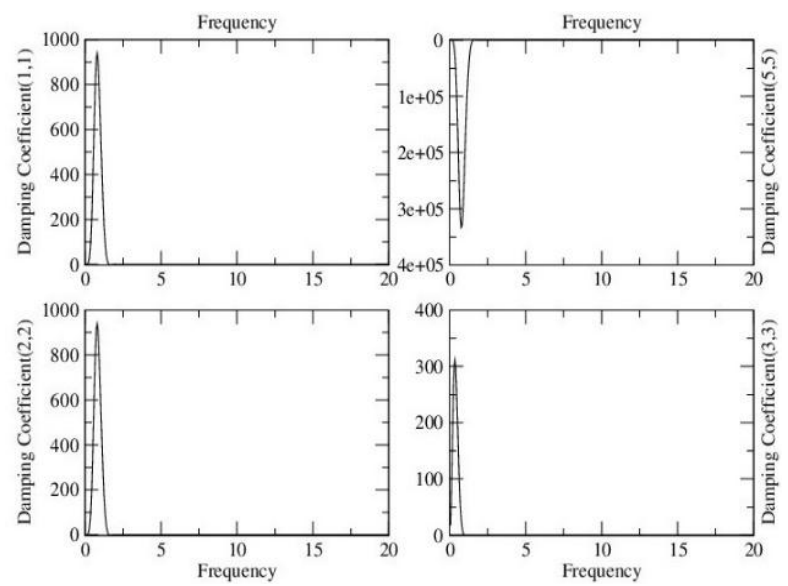

Figure 2. Damping Matrices, MIT/NREL TLP, Submerged

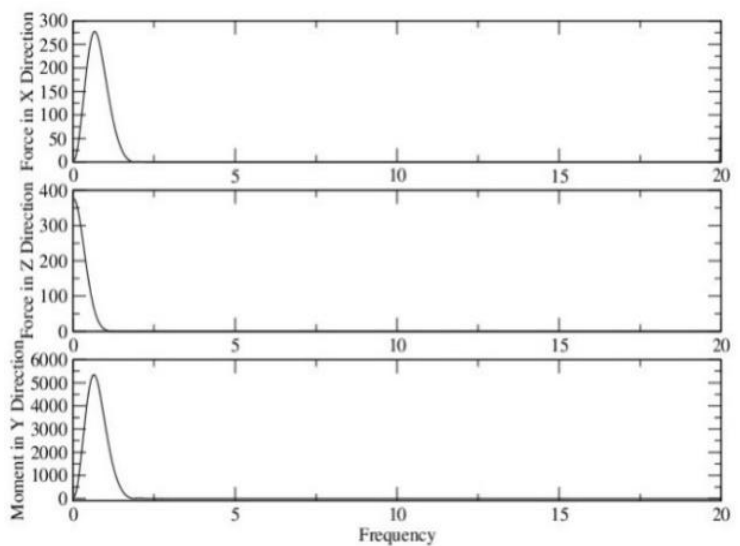

Figure 3. Exciting Forces, MIT/NREL TLP, Submerged

Also, in Fig. 2 and Fig. 5, plots of non-dimensional damping coefficients are presented. In Fig. 3 and Fig. 6, forces in the $\mathrm{x}$ and $\mathrm{z}$ directions and the moment in the $\mathrm{y}$ direction are plotted. The $\mathrm{x}$-component of force increases since wave hits the platform.

The results of experiment on scaled platform is presented in this chapter. The waves with different frequencies were generated and forces were measured and compared with theory in Fig. 7 - Fig. 9.

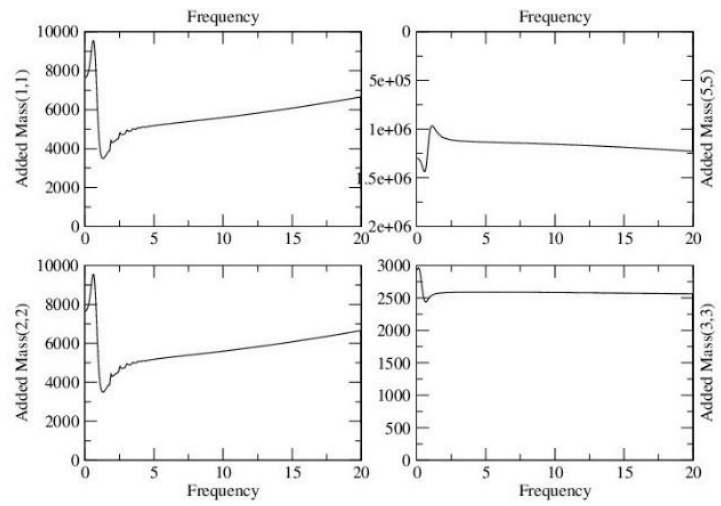

Figure 4. Added Mass Matrices, MIT/NREL TLP, Surface
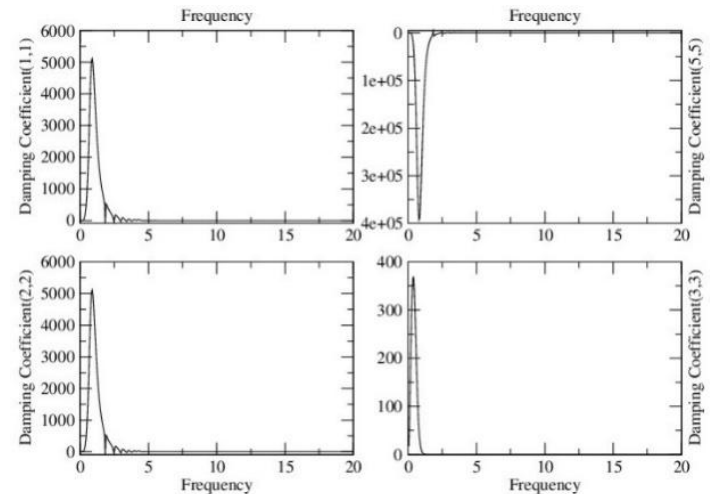

Figure 5. Damping Matrices, MIT/NREL TLP, Surface

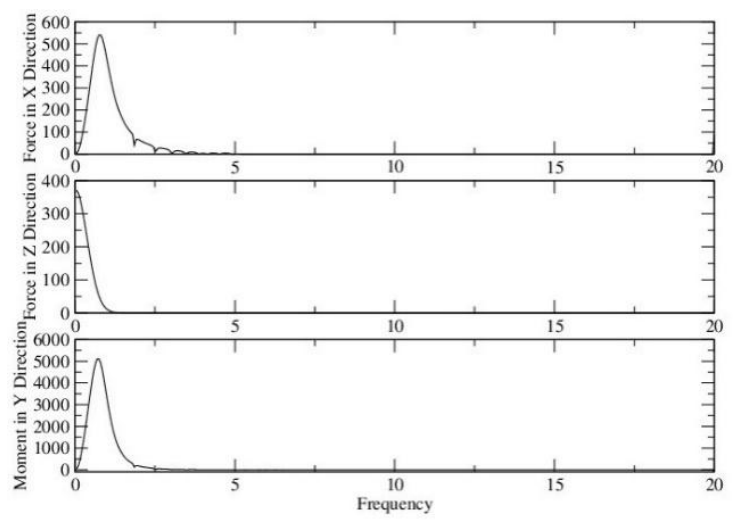

Figure 6. Exciting Forces, MIT/NREL TLP, Surface.

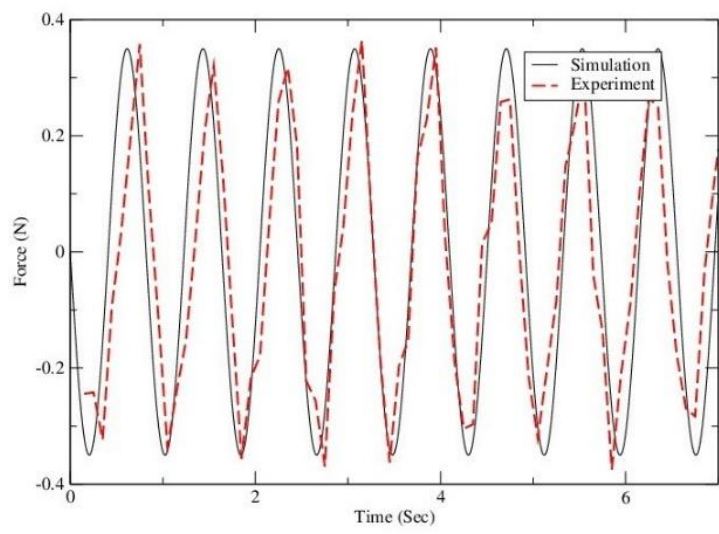

Figure 7. Wave Force on a Single Cylinder (Wave Frequency $=1.2 \mathrm{~Hz}$ ) 


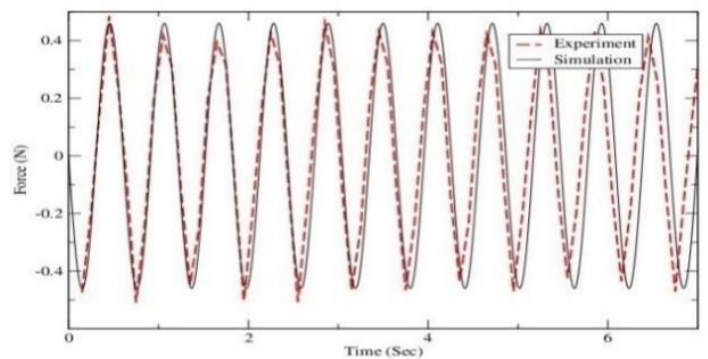

Figure 8. Wave Force on a Single Cylinder (Wave Frequency $=1.6 \mathrm{~Hz}$ )

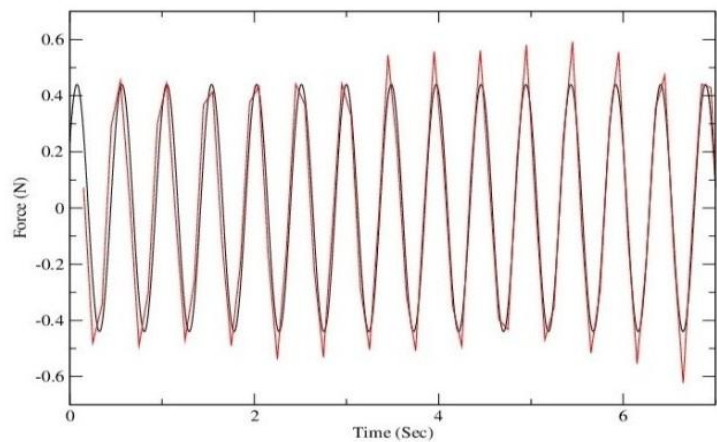

Figure 9. Wave Force on a Single Cylinder (Wave Frequency $=2.1 \mathrm{~Hz}$ )

\section{DISCUSSION}

It is understood from simulation and experiments in this study that the force from wave on surface-pierced platform is higher compared to force on submerged platform. Consequently, submerged platform' motion is reduced compared to surface-pierced platform. On the other hand, submerged platform's stability is not assisted by water plane area. Also, it is understood that as depth of water increases, the maximum response occurs higher frequency.

\section{CONCLUSION}

In this paper, a numerical and experimental method developed to model offshore wind turbine. Initially, the wind turbine properties were obtained using numerical code. Then, hydrodynamic forces on the platform was calculated numerically. All of these calculations were verified using experiments that were conducted. Finally, the methods were used to study two platforms. It was understood that submerged platforms are more stable compared to surface-pierced platforms.

\section{REFERENCES}

[1] S. Akhlaghi, M. Sarailoo, M. Rezaeiahari, H. A. Sangrody, "Study of Sufficient Number of Optimal Tilt Angle Adjustment to Maximize Residential Solar Panels Yield" IEEE Power and Energy Conference at Illinois (PECI), 2017. Illinois, USA, Feb, 2017.

[2] Sarfi, V., Niazazari, I., \& Livani, H. (2016, September). Multiobjective fireworks optimization framework for economic emission dispatch in microgrids. In North American Power Symposium (NAPS), 2016 (pp. 1-6). IEEE.

[3] Heronemus, W. E. (1972). Pollution-Free energy from the offshore winds. Marine Technology Society
[4] R. JalilzadehHamidi and H. Livani (2015), A travelling wave-based fault location method for hybrid three-terminal circuits, IEEE General Meeting, Denver, Co, USA, pp. 1-5.

[5] R. JalilzadehHamidi and H. Livani (2017). Traveling-wave-based fault-location algorithm for hybrid multiterminal circuits, IEEE Trans., Power Delivery, 32(1), pp. 135-144, 2013.

[6] Jonkman, J. M. (2007). Dynamics modeling and loads analysis of an offshore floating wind turbine. ProQuest.

[7] Wayman, E. N. (2006). Coupled dynamics and economic analysis of floating wind turbine systems (Doctoral dissertation, Massachusetts Institute of Technology).

[8] Niazazari, I., Vahidi, B., \&Abyaneh, H. A. (2013), Loss reduction of wind turbine with optimization of blade length using genetic algorithm. Science International, 25(4), pp. 807-811.

9] Jafari-Shiadeh, S. M., \&Ardebili, M. (2013, February). Analysis and comparison of axial-flux permanent-magnet brushless-DC machines with fractional-slot concentrated-windings. In Power Electronics, Drive Systems and Technologies Conference (PEDSTC), 2013 4th (pp. 72-77). IEEE.

[10] Shiadeh, S. J., Ardebili, M., \&Moamaei, P. (2015, February). Three-dimensional finite-element-model investigation of axial-flux PM BLDC machines with similar pole and slot combination for electric vehicles. In Power and Energy Conference at Illinois (PECI), 2015 IEEE (pp. 1-4). IEEE.

[11] Khalili, A., Jha, R., \&Samaratunga, D. (2016). Spectrally formulated user-defined element in conventional finite element environment for wave motion analysis in 2-D composite structures. European Journal of Computational Mechanics, 1-29.

[12] Akhlaghi, S., Zhou, N., \& Huang, Z. (2016). A Multi-Step Adaptive Interpolation Approach to Mitigating the Impact of Nonlinearity on Dynamic State Estimation. IEEE Transactions on Smart Grid.

[13] Khalili, A., Samaratunga, D., Jha, R., Lacy, T. E., \&Gopalakrishnan, S. (2015, November). WSFE-based User-Defined Elements in ABAQUS for Modeling 2D Laminated Composites with Complex Features. In American Society of Composites-30th Technical Conference.

[14] Sarfi, V., Hemmati, V., \&Arabshahi, M. M. (2014, September). Simulation of PTC devices as fault current limiters in power systems by finite element method. In High Voltage Engineering and Application (ICHVE), 2014 International Conference on (pp. 1-4). IEEE.

[15] Gharghabi, P., Lee, J., Mazzola, M. S., \& Lacy, T. E. (2016). Development of an Experimental Setup to Analyze Carbon/Epoxy Composite Subjected to Current Impulses. In Proceedings of the American Society for Composites: Thirty-First Technical Conference.

[16] Gharghabi, P., Dordizadeh, P., \&Niayesh, K. (2011). Impact of metal thickness and field shaper on the time-varying processes during impulse electromagnetic forming in tubular geometries. Journal of the Korean Physical Society, 59(61), 3560-3566.

[17] WAMIT User Guide. Cambridge, Massachusetts: WAMIT, Inc, 2013.

[18] Masoomi, M., Gao, X., Thompson, S. M., Shamsaei, N., Bian, L., \&Elwany, A. (2015, November). Modeling, simulation and experimental validation of heat transfer during selective laser melting. In ASME 2015 International Mechanical Engineering Congress and Exposition American Society of Mechanical Engineers.

[19] Masoomi, M. (2014). Numerical modeling of thermal effects during selective laser melting. In 10th Mississippi State Conference on Differential Equations and Computational Simulations.

[20] Masoomi, M. (2014). Model development and load analysis of an offshore wind turbine.

[21] Rad, M. G., Rahmani, M., Gharghabi, P., Zoghi, A., \& Hosseinian, S. H. (2017). Scheduling a Wind Hydro-Pumped-Storage Unit Considering the Economical Optimization. American Journal of Electrical and Electronic Engineering, 5(1), 16-22.

[22] Peyman Dordizadeh, B., Gharghabi, P., \& Niayesh, K. (2011). Dynamic analysis of a fast-acting circuit breaker (Thompson) drive mechanism. Journal of the Korean Physical Society, 59(6), 3547-3554.

[23] Shanthala, K., \& Sreenivasa, T. N. (2016). Stress Analysis of Field Shaper in ElectroMagnetic Welding. International Journal of Scientific Research, 4(5).

[24] Jonkman, J. M. (2007). Dynamics modeling and loads analysis of an offshore floating wind turbine. ProQuest.

[25] Masoomi, M., Thompson, S. M., Shamsaei, N., Bian, L., (2016). Effects of Inter-Layer Time Interval on Temperature Gradients in Direct Laser Deposited Ti-6Al-4V. In 27th Int. Solid Free. Fabr. Symp., 2016. 